\title{
Scoliosis epidemiology is not similar all over the world: a study from a scoliosis school screening on Chongming Island (China)
}

Qing $\mathrm{Du}^{1 \dagger}$, Xuan Zhou $^{1+}$, Stefano Negrini ${ }^{2,3+}$, Nan Chen ${ }^{1}$, Xiaoyan Yang ${ }^{1}$, Juping Liang ${ }^{1}$ and Kun Sun ${ }^{4^{*}}$

\begin{abstract}
Background: School scoliosis screening has been carried out around the world. The screen program has never been performed on Chongming Island, the third largest island in China and characterized less population exchange with the rest of China. This study was designed to examine scoliotic parameters in children from Chongming Island and determine whether the parameters differed from those of the published data.

Methods: A total of 6824 children (3477 boys and 3347 girls) aged from 6 to 17 were recruited. The screen included Adam's test and scoliometer measurements. Posteroanterior radiographic evaluation was performed if trunk rotation was $5^{\circ}$ or more.

Results: One hundred seventy two were confirmed with Cobb angle of $10^{\circ}$ or more; the prevalence was $2.52 \%$, higher in girls $(3.11 \%)$ than in boys $(1.96 \%)(p<0.05)$. There was a weak positive correlation between prevalence and age. Majority curves were minor (from 10 to $19^{\circ}$ ). The most common thoracic curve was right curve $(60.3 \%$ of all thoracic curves), while the most common thoracolumbar (75.5 \%) and lumbar curves (64.7 \%) were left curves.

Conclusions: The prevalence of scoliosis on Chongming Island was $2.52 \%$. This study indicates that epidemiology of scoliosis has regional variation, and genetic differences may contribute such difference.
\end{abstract}

Keywords: School scoliosis screening, Scoliosis, Prevalence, China

\section{Background}

Scoliosis is usually detected through a school screening program. School scoliosis screening (SSS) is considered a powerful tool that can identify individuals with unrecognized scoliosis at an early stage when less invasive treatment is more effective [1]. SSS can also generate invaluable data regarding not only the prevalence but also the natural history of scoliosis, which contribute significantly to the research for idiopathic scoliosis etiology [2]. The progression of untreated idiopathic scoliosis in patients during periods of rapid growth may result in severe deformity, which may be accompanied by restrictive

\footnotetext{
* Correspondence: sunkunxh@126.com

${ }^{\dagger}$ Equal contributors

${ }^{4}$ Department of Pediatric cardiology, Xin Hua Hospital Affiliated to Shanghai Jiao Tong University School of Medicine, Shanghai 200092, China Full list of author information is available at the end of the article
}

pulmonary disease [3-5], and social psychogenic problems $[6,7]$. Early detection by screening programs and application of an effective orthopedic and rehabilitation treatment are essential for avoiding scoliosis progression, minimizing the need for an operation [8-13], and reducing associated costs [14-16].

SSS is conducted around the world [2]. In Europe, SSS dates back to the early 20th century. In the USA, SSS has been conducted since the early 1960s; currently, less than half of the states have legislated school screening. In Japan, school screening programs for scoliosis are mandatory by law. In the past, SSS was performed in many countries. In China, SSS was not performed until 1985. As of 2012, only three provinces and one municipality in China had conducted SSS [17-21]. At present, a SSS program is not included in the Chinese School Health Service, and there is no recommendation to include one. There are no 
national screening programs in China: the only established SSS program is in Hong Kong. To date, SSS has never been performed on Chongming Island, which is the third largest island in China, with a population of 703,722.

Although the pathogenesis of idiopathic scoliosis remains controversial, genetic factors are thought to play key roles in the development of idiopathic scoliosis etiology [22]. Genetic factors in China could be different than in other places and may be reflected in differences in prevalence. Race may influence an individual's natural spinopelvic alignment [23]. The prevalence of scoliosis differs among races [24, 25], and curve severity is associated with race [25, 26]. Kebaish et al. [25] found that the prevalence of scoliosis was $11.1 \%$ for whites and $6.5 \%$ for African Americans. Zavatsky et al. [26] found that curve magnitude was greater in black patients than in white patients $\left(33^{\circ}\right.$ vs. $\left.28^{\circ}\right)$. A study found that the prevalence of scoliosis in Chinese girls was significantly higher than in Malay and Indian girls aged 11 to 12 and 16 to 17 years [24]. Therefore, further studies are necessary to confirm the prevalence and distribution of various scoliotic parameters according to patient age and gender in a Chinese population.

The aim of the present study was to examine scoliotic parameters (such as patients' age, gender, curve magnitude, curve type, and curve side) in children from Chongming Island, an area with few population exchanges with the rest of China, through a scoliosis school screening program and to determine whether the parameters differed from that of the previously published data.

\section{Methods}

\section{Preliminary work}

After permission was obtained from the Chongming Ministries of Education and Health, each school was contacted. It was essential to obtain the support of school physicians and the collaboration of the teachers and parents. Two months before starting the program, a member of the screening team gave a detailed explanation of the aims, importance, methods, and procedure of SSS to school physicians and teachers. Information leaflets were sent to all schools on Chongming Island, as well as to local education and health authorities, teachers, and parents. The parents were informed by means of a letter that described the intentions of the study, the clinical importance of early detection, and the details of the examination procedure. Informed consents were obtained from the parents of the students participating in the study.

Once this phase was completed, four scoliosis screening teams, consisting of a senior physician, a resident, a nurse, and a medical student, were organized and trained in screening methods and childhood behavior. By alternating the screening teams, fatiguing the medical staff was avoided. Before the screening, the forms were forwarded to the schools and the children were instructed to fill in their biographical information.

\section{School screening}

The screening took place during regular lesson time to avoid any psychological stress, usually with the assistance of the school physician. Small groups of no more than ten children were admitted into the screening room at a time. Each child brought his or her completed data form. The boys and girls were examined separately, and each patient was screened in private. The children wore only a slip or undershorts for the examination.

The medical student recorded the children's physical attributes. The child then proceeded to the resident or the senior physician, who checked for spinal and other deformities. A standard clinical examination preceded the screening tests. The screening examination began with the child standing up straight with their back to the examiner, head up and the arms relaxed at the sides. With the child in this position, we looked for shoulder asymmetries, scapular prominence, unequal waistline, and lower limb length inequality. Any abnormality of the torso or the lower extremities was recorded. The Adam's forward bending test was then performed to check for signs of vertebral rotation and lateral deviation of the spine.

The parameters that were recorded included biographical information (name, date of birth, and family address), physical attributes (age of menarche for the girls, patient weight, patient height when standing), and abnormalities involving the trunk or spine (e.g., humps in the rib or lumbar region, discrepancies between the shoulders or between the hips, and imbalance of the torso or spine).

\section{Rescreening and radiographic evaluation}

Healthy children exhibit symmetric shoulder levels, scapular prominence and waistline, equal length of lower limbs, and no vertebral rotation and lateral deviation of the spine. The asymmetry of the shoulder levels, scapular prominence and waistline, lower limb length inequality, and vertebral rotation and lateral deviation of the spine were recorded as absent or present. If any abnormality of all these signs was noted, it was considered positive sign. Children who showed at least one positive sign were re-examined by a senior physician to confirm the criteria for referral. Children in whom scoliosis was suspected were requested for re-examination, at which time a second Adam's forward bending test was performed. The examiner compared the two sides of the torso at the thoracic, thoracolumbar, and lumbar levels. If any difference in height was noted, the angle of trunk rotation (ATR) was measured with a scoliometer, which is currently the best tool available for scoliosis screening. [10] A difference of five degrees or more was considered to be a positive finding on the bending test. 
The children were referred for radiographic evaluation only if the examiner confirmed a positive result on the bending test. Posteroanterior radiographs were made (with the patient standing) at a local hospital or at Xin Hua hospital, which is affiliated with Shanghai Jiao Tong University School of Medicine. The curve magnitude was immediately measured in the coronal plane using the Cobb method. A curve of $10^{\circ}$ or more was defined as scoliosis, as specified by the Scoliosis Research Society (SRS) and the International Scientific Society on Scoliosis Orthopaedic and Rehabilitation Treatment (SOSORT) guidelines [27]. The Cobb angle, curve type, and curve side of the scoliosis were recorded.

\section{Screening population}

In our screening program, we included primary, junior high and senior high school children (aged 6-17 years), excluding grade three of senior high school. During the 2012 and 2013 academic years, 32,835 students (16,727 boys and 16,108 girls) aged 6 to 17 years were registered by the Educational Authorities on Chongming Island. There were a total of 76 schools on Chongming Island, including 40 primary schools, 34 junior high schools and 8 senior high schools.

In the present study, class was taken as a unit for cluster random sampling. A serial number was given to each class in each grade at each school. The class was then screened according to the random number created by the computer. We randomly sampled one class from each grade at each school. We planned to sample 40 classes from grades one through five in primary schools, 34 classes from grades one through four in junior high schools, and 8 classes from grades one to two in senior high schools. Three hundred fifty-two classes were randomly sampled from each grade of 40 primary schools (5 grades), 34 junior high schools (4 grades) and 8 senior high schools (2 grades). Exclusion criteria for classes included 1 or more children in a class with an ATR of $5^{\circ}$ not having an X-ray taken, and the X-ray results of 1 or more children in a class not being collected. This was due to parents either refusing to have X-rays performed on their child or taking their child elsewhere to take a radiograph. In the end, 247 classes were included and 105 were excluded. There were 3477 boys and 3347 girls in the included population, while there were 1517 boys and 1391 girls in the excluded population. An ATR of $5^{\circ}$ or more was measured in 442 members of the included population and 171 of the excluded population. There was no significant difference in gender and the rate of children with an ATR of $5^{\circ}$ or more between the included and excluded populations. The loss rate was $29.9 \%$.

A total of 6824 children aged 6 to 17 years were screened from April through November 2012, which corresponds to $20.8 \%$ of the relevant population on Chongming Island.

\section{Analysis of data}

All parameters were recorded on a computer using Epidata 2.0. To calculate the prevalence rates, a curve of $10^{\circ}$ or more was used as a cutoff point. All analyses were conducted using SPSS v.17.0. Chi-squared testing was used to identify statistically significant differences in the prevalence, the distribution of curve parameters and the variables of age and gender. Logistic regression analysis was used to identify correlations between the prevalence of scoliosis and the variables of age and gender. Linear regression analysis was used to identify correlations between curve magnitude and age. An effect size greater than 0.8 was considered large, approximately 0.5 was considered moderate, and less than 0.2 was considered small [28]. All hypothesis testing was considered significant at $p<0.05$.

\section{Results}

Out of the 6824 children in the screened population, 442 (201 boys and 241 girls) had clinical signs of scoliosis and were referred for radiological evaluation. A total of 172 children had radiographic evidence of scoliosis (a curve of $10^{\circ}$ or more), demonstrating a prevalence rate of $2.52 \%$ (Table 1 ). Logistic regression analysis showed that there was a significant association between the prevalence of scoliosis and the variables of age and gender. Linear regression analysis showed that there was a very weak, yet statistically significant, correlation between age and Cobb angle (Fig. 1). The correlation coefficient was $0.18(p=0.016)$.

Of the 172 scoliosis patients (see Additional file 1), 68 were boys and 104 were girls. Girls had a significantly higher prevalence of scoliosis (3.11\%) than boys (1.96 \%). Gender showed no statistically significant difference in the average Cobb angle. The male/female ratio was 1:1.5 overall but varied according to the magnitude of the curve (1:1.5 for curves of 10 to $19^{\circ}$ and 1:2.3 for curves of 20 to $39^{\circ}$ ).

We found that 162 (94.2\%) of the scoliosis patients had mild curves $\left(10\right.$ to $\left.19^{\circ}\right)$, and 10 (5.8 \%) had moderate curves $\left(20\right.$ to $\left.39^{\circ}\right)$. Most of the curves were small. There was no significant difference in the distribution of curve magnitude and age group. Gender also showed no statistically significant difference in curve magnitude: $95.6 \%$ of boys (65/68) and $93.3 \%$ of girls (97/104) had mild curves (Table 2).

In assessing the curve type among the 172 scoliosis patients, we found that 68 (39.5\%) had thoracic curves, 53 (30.8\%) had thoracolumbar curves, 34 (19.8\%) had lumbar curves, and 17 (9.9\%) had double curves. Thoracic curves were the most common type of curve identified, followed by thoracolumbar curves. Single curves occurred nine times more frequently than double curves. There was a statistically significant difference in the distribution of curve type and age group. Among age groups, most groups were more likely to have thoracic curves. However, the 
Table 1 Clinical and radiologically detected scoliosis in children aged 6 to 17 years according to age and gender

\begin{tabular}{|c|c|c|c|c|c|}
\hline Demographic variable & $\begin{array}{l}\text { No. of children } \\
\text { included }(N=6824)\end{array}$ & $\begin{array}{l}\text { No. of children referred } \\
\text { for radiograph }(N=442)\end{array}$ & $\begin{array}{l}\text { No. of children in which } \\
\text { scoliosis was radiologically } \\
\text { detected }(N=172)\end{array}$ & Prevalence of scoliosis (\%) & $\begin{array}{l}\text { Average Cobb } \\
\text { angle (Degrees) }\end{array}$ \\
\hline \multicolumn{6}{|l|}{ Age } \\
\hline $6 \sim$ & 163 & 15 & 4 & 2.45 & 12.5 \\
\hline $7 \sim$ & 873 & 57 & 16 & 1.83 & 11.3 \\
\hline $8 \sim$ & 853 & 39 & 12 & 1.41 & 12.1 \\
\hline $9 \sim$ & 903 & 59 & 24 & 2.66 & 12.0 \\
\hline $10 \sim$ & 849 & 60 & 23 & 2.71 & 12.4 \\
\hline $11 \sim$ & 746 & 47 & 16 & 2.14 & 15.3 \\
\hline $12 \sim$ & 592 & 44 & 17 & 2.87 & 13.7 \\
\hline $13 \sim$ & 601 & 50 & 19 & 3.16 & 12.1 \\
\hline $14 \sim$ & 529 & 29 & 18 & 3.40 & 13.1 \\
\hline $15 \sim$ & 250 & 10 & 8 & 3.20 & 15.3 \\
\hline $16 \sim$ & 247 & 18 & 10 & 4.05 & 15.1 \\
\hline 17 & 218 & 14 & 5 & 2.29 & 13.0 \\
\hline \multicolumn{6}{|l|}{ Gender } \\
\hline Boys & 3477 & 201 & 68 & 1.96 & 12.5 \\
\hline Girls & 3347 & 241 & 104 & 3.11 & 13.3 \\
\hline
\end{tabular}

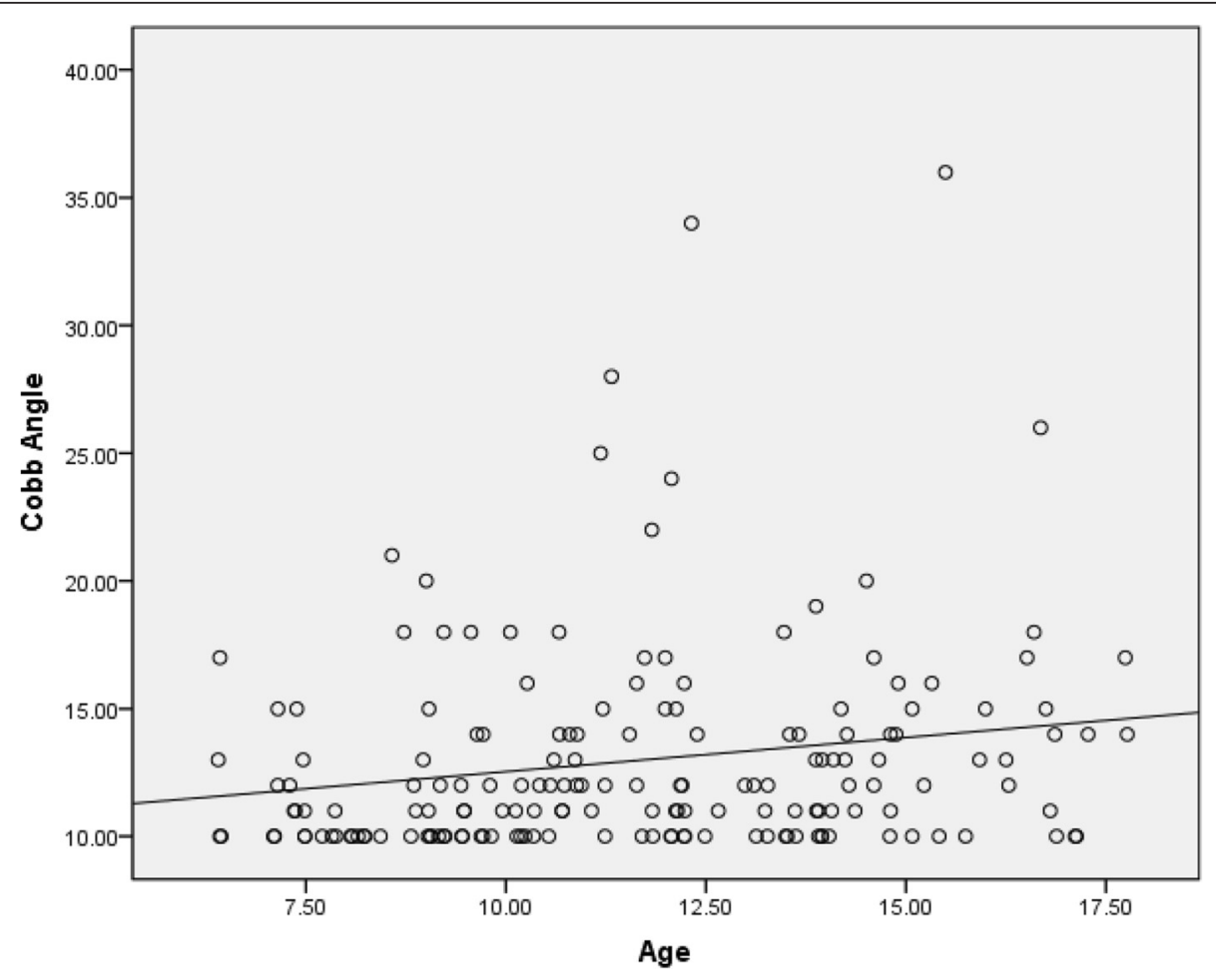

Fig. 1 Correlation between age and Cobb angle 
Table 2 Curve magnitude by age and gender among the 172 patients with scoliosis

\begin{tabular}{|c|c|c|}
\hline \multirow{2}{*}{$\begin{array}{l}\text { Demographic } \\
\text { variable }\end{array}$} & \multicolumn{2}{|c|}{ No. of scoliosis patients with the following curve magnitudes } \\
\hline & Cobb Angle $\left(10\right.$ to $\left.19^{\circ}\right)(N=162)$ & Moderate $\left(20\right.$ to $\left.39^{\circ}\right)(N=10)$ \\
\hline \multicolumn{3}{|l|}{ Age } \\
\hline $6 \sim$ & 4 & 0 \\
\hline $7 \sim$ & 16 & 0 \\
\hline $8 \sim$ & 11 & 1 \\
\hline $9 \sim$ & 23 & 1 \\
\hline $10 \sim$ & 23 & 0 \\
\hline $11 \sim$ & 13 & 3 \\
\hline $12 \sim$ & 15 & 2 \\
\hline $13 \sim$ & 19 & 0 \\
\hline $14 \sim$ & 17 & 1 \\
\hline $15 \sim$ & 7 & 1 \\
\hline $16 \sim$ & 9 & 1 \\
\hline 17 & 5 & 0 \\
\hline \multicolumn{3}{|l|}{ Gender } \\
\hline Boys & 65 & 3 \\
\hline Girls & 97 & 7 \\
\hline
\end{tabular}

Table 3 Curve type by age, gender and curve side among the 172 patients with scoliosis

\begin{tabular}{|c|c|c|c|c|}
\hline \multirow{2}{*}{$\begin{array}{l}\text { Demographic } \\
\text { variable }\end{array}$} & \multicolumn{3}{|l|}{ Single curve } & \multirow{2}{*}{$\begin{array}{l}\text { Double curve } \\
(N=17)\end{array}$} \\
\hline & Thoracic $(N=68)$ & Thoracolumbar $(N=53)$ & Lumbar $(N=34)$ & \\
\hline \multicolumn{5}{|l|}{ Age } \\
\hline $6 \sim$ & 1 & 3 & 0 & 0 \\
\hline $7 \sim$ & 7 & 6 & 3 & 0 \\
\hline $8 \sim$ & 8 & 3 & 1 & 0 \\
\hline $9 \sim$ & 9 & 13 & 1 & 1 \\
\hline $10 \sim$ & 8 & 5 & 5 & 5 \\
\hline $11 \sim$ & 3 & 7 & 3 & 3 \\
\hline $12 \sim$ & 4 & 5 & 6 & 2 \\
\hline $13 \sim$ & 9 & 3 & 6 & 1 \\
\hline $14 \sim$ & 9 & 5 & 2 & 2 \\
\hline $15 \sim$ & 2 & 3 & 3 & 0 \\
\hline $16 \sim$ & 4 & 0 & 3 & 3 \\
\hline 17 & 4 & 0 & 1 & 0 \\
\hline \multicolumn{5}{|l|}{ Gender } \\
\hline Boys & 28 & 25 & 11 & 4 \\
\hline Girls & 40 & 28 & 23 & 13 \\
\hline \multicolumn{5}{|l|}{$\begin{array}{l}\text { Side } \\
\text { (major curve) }\end{array}$} \\
\hline Right & 41 & 13 & 12 & 10 \\
\hline Left & 27 & 40 & 22 & 7 \\
\hline
\end{tabular}


6 year-old, 9 year-old and 11 year-old groups were more likely to have thoracolumbar curves, and the 12 year-old groups were more likely to have lumbar curves. Gender showed no statistically significant difference in curve type: boys and girls had statistically equivalent distributions of curve type (Table 3).

Of the cases in the present study, thoracic curves were right in $60.3 \%$, thoracolumbar curves were left in $75.5 \%$, lumbar curves were left in $64.7 \%$, and major curves of double curves were right in $58.8 \%$ (Table 3). There was a significant difference in the distribution of curve side and curve type.

There was a significant positive correlation between ATR and Cobb angle $(r=0.435, P=0.000)$. ATR ranged from $5^{\circ}$ to $18^{\circ}$, and Cobb angle ranged from $10^{\circ}$ to $36^{\circ}$. Mean ATR was $5.8^{\circ} \pm 1.8^{\circ}$. Mean Cobb angle was $12.9^{\circ} \pm 4.1^{\circ}$. In thoracic curves, there was a significant positive correlation between ATR and Cobb angle $(r=0.256, P=0.035)$. In thoracolumbar curves, there was a significant positive correlation between ATR and Cobb angle $(r=0.751, P=$ $0.000)$. In lumbar curves, there was a significant positive correlation between ATR and Cobb angle $(r=0.512, P=$ 0.002). There was no significant correlation between ATR and Cobb angle in double curves $(r=-0.010, P=0.969)$.

\section{Discussion}

The prevalence rate of scoliosis in schoolchildren from Chongming Island aged 6 to 17 years was $2.52 \%$. There is an increase in the scoliosis prevalence of schoolchildren on Chongming Island compared to those reported by previous studies in other provinces of China (0.70 to $2.09 \%$ ) [17-21, 29], Singapore (0.38 to $1.2 \%)$ [24, 30, 31], Japan $(0.87 \%)$ [32], Turkey (0.25 \%) [16], Saudi Arabia (0.78 \%) [33], India (0.13 \%) [34], Minnesota (1.2\%) [9], Brazil $(1.4-2.2 \%)$ [35, 36], Greece $(1.7 \%)[37,38]$, and Nigeria (1.2\%) [39]. The prevalence of scoliosis in our study is lower than those reported from Korea (3.26 \%) [40], and Australia (3.1\%) [41]. In the Australian study [41], a different criterion (the presence of scoliosis was defined as a Cobb angle of $5^{\circ}$ or more) was used. Similar criteria were used in the Korean study [40], but the screening population (children aged 10 to 14 years) was different from our population (children aged 6 to 17 years).

We found that there was a positive, but very weak, correlation between scoliosis and age. This finding is similar to that of reports from Singapore and Tokyo [30-32], but differs from that of the report from Korea [40]. Studies in Singapore found that there was an increasing trend in the prevalence of idiopathic adolescent scoliosis among female students between the ages of 9 and 14 years [30, 31]. Ueno et al. [32] reported that the prevalence of scoliosis in girls in Tokyo increased from $0.78 \%$ at 11 to 12 years of age to $2.51 \%$ at 13 to 14 years of age. Suh et al. [40] found that the prevalence of scoliosis in girls in Korea was higher at
10 to 12 years of age than at 13 to 14 years of age $(5.57 \%$ vs. $3.90 \%)$. However, logistic regression analysis has never been used to identify correlations between the prevalence of scoliosis and age in all of these previous studies. Age group analysis showed no statistically significant difference in curve magnitude or curve side.

We also found that girls had a significantly higher prevalence of scoliosis than boys. This finding is in agreement with those described in previous studies [30, 32, 38] Gender was not associated with curve magnitude, curve type or curve side. The male/female ratio in the present study was 1:1.5, similar to that reported from the Shanxi Province of China (1:1.2) in 1995 [18]. In recent studies, Jenyo et al. [39] reported the highest male/female ratio (1:0.7) in Nigeria; however, the sample size was too small (a little more than 400) to be significant. Most studies reported a male/female ratio between 1:2.1 and 1:11.6 (1:2.1 for Greece, 1:2.4 for Korea, 1:2.6 for Turkey, 1:4.6 for Singapore, and 1:11.6 for Japan) [16, 30, 32, 38, 40], Based on recent publications, the male/female ratio in this study is higher than most. It seems that the proportion of male patients is higher in China.

The findings of the present study indicate that small scoliotic curves $\left(10\right.$ to $\left.19^{\circ}\right)$ are the most common (94.2 \%). This finding is in agreement with those described in reports from Korea, Tokyo, Turkey and India [16, 32, 34, 40].

The most common types of scoliotic curves in the present study were thoracic and thoracolumbar. This finding is in agreement with those described in reports from Brasil, Singapore, Nigeria and Crete [30, 35, 37, 39], but differs from those described in reports from Greece, where the proportion of single thoracolumbar and lumbar curves greatly outweighed that of all others [38]. In contrast, the prevalence of thoracic curves reported from Korea (47.6\% of 37,339 scoliotic curves) was greater than that reported in the present study (39.5\% of 172 scoliotic curves) [40]. In the present study, the distribution of curve type varied according to age. The finding that double curves constitute less than $10 \%$ of the curves observed is in agreement with that reported from Korea [40].

In this study, most of thoracolumbar and lumbar curves were to the left. Thoracic curves were right in $60.3 \%$, thoracolumbar curves were left in $75.5 \%$, lumbar curves were left in $64.7 \%$, and major curves of double curves were right in $58.8 \%$. These findings differ from those of the epidemiological study from Greece [38]. Soucacos et al. [38] found that $75.5 \%$ of thoracic curves were right, $66.3 \%$ of thoracolumbar curves were left, and $76.2 \%$ of lumbar curves were left. It seems that there are fewer right thoracic curves, more left thoracolumbar curves, and fewer left lumbar curves in Chinese scoliosis patients.

A positive correlation between ATR and Cobb angle was found in this study. The correlation coefficient between 
ATR and Cobb angle was consistent with the previous studies [42, 43]. The correlation between ATR and Cobb angle in thoracic curves was weaker than that reported by Carlson [44]. However, the curve magnitude in Carlson's study $\left(29^{\circ}-79^{\circ}\right)$ was larger than that in present study $\left(10^{\circ}-36^{\circ}\right)$.

The percentage of schoolchildren referred for radiographs in the present study $(6.5 \%, 442$ of 6824) is within the range reported from other countries (0.9 to $9.6 \%$ ) $[9,16,18,19,37,40]$. In this study, we have reported a prevalence that we think is representative of the scoliotic population on Chongming Island and have further checked factors such as age, male/female ratio, curve magnitude, curve type, and curve side. Scoliosis is common in schoolchildren on Chongming Island and therefore poses a major public health problem. SSS appears to be an effective means for early detection (identification of a large number of previously undiagnosed curves), identification of children at a high risk for curve progression and selection of an effective orthopedic and rehabilitation treatment $[9,16,37,39]$. The present study provides evidence to support the case for including SSS in annual school-based health screening programs in primary, junior and senior high schools on Chongming Island.

This study was not without limitations. The complete lost rate was $29.9 \%$ : 3152 of 9976 children were excluded.

Additional investigations are underway to refine our understanding of scoliosis in the Chinese population: an epidemiological study of a larger population cohort and a follow-up study of the patients in our study who were identified as having scoliosis.

\section{Conclusions}

We found that the overall prevalence of scoliosis was $2.52 \%$ in Chongming Island. The percentages of curve magnitude and type were comparable. The following points in our study differed from the findings of research in other countries: (1) the proportion of male scoliosis patients was increased, (2) most of thoracolumbar and lumbar curves were to the left, and (3) the prevalence rate of scoliosis was associated with age. According to these results, epidemiological regional variability, possibly with genetic basis, should be considered.

All the characteristics we found may contribute to draw up health policies for the local government. They could help to develop a rehabilitation program for these patients in an early stage, and also improve their spinal health.

\section{Additional file}

Additional file 1: The raw data of 172 scoliosis patients. (XLSX $23 \mathrm{~kb}$ )

\section{Abbreviations}

ATR, angle of trunk rotation; SOSORT, the International Scientific Society on Scoliosis Orthopaedic and Rehabilitation Treatment; SRS, scoliosis research society; SSS, school scoliosis screening

Acknowledgements

This work was supported by Clinical Research Unit of Xin Hua Hospital.

\section{Funding}

It was funded by the Science and Technology Committee of Shanghai Grant No.13401903400, the Academic Leader Plan of Shanghai Disabled Persons Federation System Cultivating Excellent Rehabilitation Individual Plan, and Key Developing Disciplines Construction Program (Rehabilitation Medicine) of

Shanghai Municipal Commission of Health and Family Planing (2015ZB0406).

Availability of data and materials

The raw data of 172 scoliosis patients was added as Additional file 1.

\section{Authors' contributions}

$\mathrm{KS}, \mathrm{QD}, \mathrm{SN}, \mathrm{XZ}$ conceived of the study and participated in its design. KS, QD, $X Z, N C, X Y$ performed the study. QD, XZ, and JL performed the statistical analysis. KS, QD, XZ drafted the manuscript. All authors read and approved the final manuscript.

\section{Authors' information}

Qing Du, MD, PhD

Xuan Zhou, MD

Stefano Negrini, MD

Nan Chen, PT

Xiaoyan Yang, MD

Juping Liang, PT

Kun Sun, MD, PhD

\section{Competing interests}

The authors declare that they have no competing interests.

\section{Consent for publication}

Not applicable.

\section{Ethics approval and consent to participate}

This study was approved by the ethics committee of the Xin Hua Hospital affiliated to the Shanghai Jiao Tong University School of Medicine and was performed in accordance with the ethical standards laid down in the 1964 Declaration of Helsinki and its later amendments. Informed consents were obtained from the parents of the students participating in the study.

\section{Author details}

${ }^{1}$ Department of Rehabilitation Medicine, Xin Hua Hospital Affiliated to Shanghai Jiao Tong University School of Medicine, Shanghai 200092, China. ${ }^{2}$ Department of Clinical and Experimental Sciences, University of Brescia, Brescia, Italy. ${ }^{3}$ IRCCS Fondazione Don Gnocchi, Milan 20141, Italy.

${ }^{4}$ Department of Pediatric cardiology, Xin Hua Hospital Affiliated to Shanghai Jiao Tong University School of Medicine, Shanghai 200092, China.

Received: 7 February 2016 Accepted: 17 June 2016

Published online: 22 July 2016

\section{References}

1. Grivas TB, Vasiliadis ES, Rodopoulos G, Kovanis I. School screening as a research tool in epidemiology, natural history and aetiology of idiopathic scoliosis. Stud Health Technol Inform. 2008;135:84-93.

2. Grivas TB, Hresko MT, Labelle H, Price N, Kotwicki T, Maruyama T. The pendulum swings back to scoliosis screening: screening policies for early detection and treatment of idiopathic scoliosis - current concepts and recommendations. Scoliosis. 2013;8:16

3. Asher MA, Burton DC. Adolescent idiopathic scoliosis: natural history and long term treatment effects. Scoliosis. 2006;1:2.

4. Koumbourlis AC. Scoliosis and the respiratory system. Paediatr Respir Rev. 2006;7:152-60.

5. McCarthy RE. Prevention of the complications of scoliosis by early detection. Clin Orthop Relat Res. 1987;222:73-8. 
6. Climent JM, Sánchez J. Impact of the type of brace on the quality of life of adolescents with spine deformities. Spine (Phila Pa1976). 1999;24:1903-8.

7. Payne 3rd WK, Ogilvie JW, Resnick MD, Kane RL, Transfeldt EE, Blum RW. Does scoliosis have a psychological impact and does gender make a difference? Spine (Phila Pa 1976). 1997;22:1380-4.

8. do Espírito Santo A, Guimarães LV, Galera MF. Prevalence of idiopathic scoliosis and associated variables in schoolchildren of elementary public schools in Cuiabá, state of Mato Grosso, 2002. Rev Bras Epidemiol. 2011;14:347-56.

9. Lonstein JE, Bjorklund S, Wanninger MH, Nelson RP. Voluntary school screening for scoliosis in Minnesota. J Bone Joint Surg Am. 1982;64:481-8.

10. Labelle H, Richards SB, De Kleuver M, Grivas TB, Luk KD, Wong HK, et al. Screening for adolescent idiopathic scoliosis: an information statement by the scoliosis research society international task force. Scoliosis. 2013;8:17.

11. Montgomery F, Willner S. Screening for idiopathic scoliosis. Comparison of 90 cases shows less surgery by early diagnosis. Acta Orthop Scand. 1993;64:456-8.

12. Weinstein $\mathrm{SL}$, Dolan LA, Wright JG, Dobbs MB. Effects of bracing in adolescents with idiopathic scoliosis. N Engl J Med. 2013;369:1512-21.

13. Willner S. A comparative study of the efficiency of different types of school screening for scoliosis. Acta Orthop Scand. 1982;53:769-74.

14. Grivas TB, Vasiliadis ES, Maziotou C, Savvidou OD. The direct cost of "Thriasio" school screening program. Scoliosis. 2007;2:7.

15. Thilagaratnam S. School-based screening for scoliosis: is it cost-effective? Singapore Med J. 2007:48:1012-7.

16. Ugras AA, Yilmaz M, Sungur I, Kaya I, Koyuncu Y, Cetinus ME. Prevalence of scoliosis and cost-effectiveness of screening in schools in Turkey. J Back Musculoskelet Rehabil. 2010;23:45-8.

17. Huang NQ, Guo HS, Liu J, Huang GX, Yang XH, Chen J, Su PQ. A survey on adolescent scoliosis in Guangzhou [in Chinese]. Zhonghua Liu Xing Bing Xue Za Zhi. 2011;32:138-41.

18. Ma X, Zhao B, Lin QK. Investigation on scoliosis incidence among 24,130 school children [in Chinese]. Zhonghua Liu Xing Bing Xue Za Zhi. 1995;16:109-10.

19. Pin LH, Mo LY, Lin L, Hua LK, Hui HP, Hui DS, et al. Early diagnosis of scoliosis based on school-screening. J Bone Joint Surg Am. 1985;67:1202-5.

20. Wang YP, Ye QB, Wu B. Result on the screening of scoliosis among school students in Beijing area [Article in Chinese]. Zhonghua Liu Xing Bing Xue Za Zhi. 1996:17:160-2.

21. Zhang GP, Li ZR, Wei XR, Cao YL, Cui QL. Screening for scoliosis among school children in Beijing. Chin Med J (Engl). 1988;101:151-4.

22. Zhou S, Qiu XS, Zhu ZZ, Wu WF, Liu Z, Qiu Y. A single-nucleotide polymorphism rs708567 in the IL-17RC gene is associated with a susceptibility to and the curve severity of adolescent idiopathic scoliosis in a Chinese Han population: a casecontrol study. BMC Musculoskelet Disord. 2012;13:181.

23. Lonner BS, Auerbach JD, Sponseller P, Rajadhyaksha AD, Newton PO. Variations in pelvic and other sagittal spinal parameters as a function of race in adolescent idiopathic scoliosis. Spine (Phila Pa 1976). 2010;35:E374-7.

24. Daruwalla JS, Balasubramaniam P, Chay SO, Rajan U, Lee HP. Idiopathic scoliosis. Prevalence and ethnic distribution in Singapore schoolchildren. J Bone Joint Surg (Br). 1985;67:182-4.

25. Kebaish KM, Neubauer PR, Voros GD, Khoshnevisan MA, Skolasky RL. Scoliosis in adults aged forty years and older: prevalence and relationship to age, race, and gender. Spine (Phila Pa 1976). 2011;36:731-6.

26. Zavatsky JM, Peters AJ, Nahvi FA, Bharucha NJ, Trobisch PD, Kean KE, et al. Disease severity and treatment in adolescent idiopathic scoliosis: the impact of race and economic status. Spine J. 2013;15:939-43.

27. Negrini S, Aulisa AG, Aulisa L, Circo AB, de Mauroy JC, Durmala J, et al. 2011 SOSORT guidelines: Orthopaedic and Rehabilitation treatment of idiopathic scoliosis during growth. Scoliosis. 2012;7:3.

28. Cohen J. Statistical power analysis for the behavioral sciences. 2nd ed. NJ: Hillsdale; 1988

29. Ji XR, Yang ZD, Yang XH, Liu DD, Ni HJ, Li M. Change of selenium in environment and risk of adolescent idiopathic scoliosis: a retrospective cohort study. Eur Rev Med Pharmacol Sci. 2013;17:2499-503.

30. Wong HK, Hui JH, Rajan U, Chia HP. Idiopathic scoliosis in Singapore schoolchildren: a prevalence study 15 years into the screening program. Spine (Phila Pa 1976). 2005;30:1188-96.

31. Yong F, Wong HK, Chow KY. Prevalence of adolescent idiopathic scoliosis among female school children in Singapore. Ann Acad Med Singapore. 2009:38:1056-63

32. Ueno M, Takaso M, Nakazawa T, Imura T, Saito W, Shintani R, et al. A 5-year epidemiological study on the prevalence rate of idiopathic scoliosis in Tokyo: school screening of more than 250,000 children. J Orthop Sci. 2011;16:1-6.
33. Abo-Bakr A, Al-Mazyiad A, Al-Hussein M, Al-Sudairy R, Krimli M, Patel PJ. Adolescent idiopathic scoliosis screening of schoolgirls. Ann Saudi Med. 1992;12:555-7.

34. Mittal RL, Aggerwal R, Sarwal AK. School screening for scoliosis in India. The evaluation of a scoliometer. Int Orthop. 1987;11:335-8.

35. Lee JY, Moon SH, Kim HJ, Park MS, Suh BK, Nam JH, Jung JK, Lee HM. The prevalence of idiopathic scoliosis in eleven year-old Korean adolescents: a 3 year epidemiological study. Yonsei Med J. 2014,55(3):773-8.

36. Nery LS, Halpern R, Nery PC, Nehme KP, Stein AT. Prevalence of scoliosis among school students in a town in southern Brazil. Sao Paulo Med J. 2010; 128:69-73.

37. Koukourakis I, Giaourakis G, Kouvidis G, Kivernitakis E, Blazos J, Koukourakis M. Screening school children for scoliosis on the island of Crete. J Spinal Disord. 1997;10:527-31.

38. Soucacos PN, Soucacos PK, Zacharis KC, Beris AE, Xenakis TA. School-screening for scoliosis. A prospective epidemiological study in northwestern and central Greece. J Bone Joint Surg Am. 1997;79:1498-503.

39. Jenyo MS, Asekun-Olarinmoye EO. Prevalence of scoliosis in secondary school children in Osogbo, Osun State, Nigeria. Afr J Med Med Sci. 2005;34:361-4.

40. Suh SW, Modi HN, Yang JH, Hong JY. Idiopathic scoliosis in Korean schoolchildren: a prospective screening study of over 1 million children. Eur Spine J. 2011;20:1087-94.

41. Chan A, Moller J, Vimpani G, Paterson D, Southwood R, Sutherland A. The case for scoliosis screening in Australian adolescents. Med J Aust. 1986;145:379-83.

42. Samuelsson L, Noren L. Trunk rotation in scoliosis. The influence of curve type and direction in 150 children. Acta Orthop Scand. 1997:68(3):273-6.

43. Amendt LE, Ause-ellias KL, Lundahl J, Wadsworth CT, Nielsen DH, Weinstein SL. Validity and reliability Testing of the Scoliometer. Phys Ther. 1990;70(2):108-17.

44. Carlson BB, Burton DC, Asher MA. Comparison of trunk and spine deformity in adolescent idiopathic scoliosis. Scoliosis. 2013;8(1):2

\section{Submit your next manuscript to BioMed Central and we will help you at every step:}

- We accept pre-submission inquiries

- Our selector tool helps you to find the most relevant journal

- We provide round the clock customer support

- Convenient online submission

- Thorough peer review

- Inclusion in PubMed and all major indexing services

- Maximum visibility for your research

Submit your manuscript at www.biomedcentral.com/submit
) Biomed Central 